\title{
The Theory and Application in Agile Project Management (APM) with Scrum
}

\author{
Yiyang Fang \\ Electronic and electrical engineering department, University College London, WC1E 6BT, London, United Kingdom \\ Corresponding author.Email: gaoming@cas-harbour.org
}

\begin{abstract}
This paper aims to use the idea of "agile" in project management to possibly avoid failure in projects for technology companies. Agile project management (APM) is a kind of new management method to keep stability and flexibility for managing innovation projects. The Scrum is one of the APM methodologies that creates collaborative and productive aspects between customers and developer. Practical applications apply the Scrum model with scrum roles and processes in accordance with theories. This method could reduce the loss for shelf-life products in Brazilian pharmaceutical company. In addition, it could be found high visibility and adaption, low risk in financial management government projects by this management approach. There are still some difficulties such as the unfamiliarity of this innovative method and lack of technical knowledge and experience.
\end{abstract}

Keywords: Agile project management (APM), Scrum, Brazilian pharmaceutical industry, government financial project.

\section{INTRODUCTION}

Increasing product complexity, technical innovation, and dynamic markets are the ordinary trends in these years, which probably reveal the uncertainty in the whole market and insufficient management system in organizations. The change of management mode is one of the necessary ways for companies to become more competitive in the market especially for the technology industry that has constant and rapid innovation. A feasible management approach for teams or even organizations is the core to increase the competitiveness of projects, which is represented on more profit margin, innovation, less risk in business and so on. APM, one of the useful management methodologies, has been disseminated widely in the software engineering and technology industry since the last decade, which is originated from the agile software development movement [1].

According to Highsmith [2], agile management can be explained as a flexible and stable ability to respond the change in a turbulent business environment. Augustine [3] indicates that APM is a way of working by constantly learning and adapting to changes according to customer needs and business environment, thus, the project team can deliver business value quickly and confidently. In DeCarlo's [4] view, APM is a management method that can be used in an uncertain and constantly changing environment and generate incremental value. Its main content is to conduct thought management, strengthen emotional communication and interaction.

According to the different definitions above, APM mainly refers to a flexible and simple method, which can realize short-term iteration and value increment.

The agile approach which focuses on business results and achieves multiple success criteria is more efficient precisely to respond to the unpredictable change in the technology industry. There are two important features emphasized by APM: Firstly, project risks are minimized due to the short iteration cycle and clear delivery definitions; secondly, searching documents are replaced by direct communication [5]. In this paper, a detailed explanation of agile methodology with Scrum will be stated in the following text including the origin, comparison with traditional approach, the Scrum roles and process and artifacts. Then, applications of the APM method in government financial management and Brazilian medicine company will be analyzed in the following context. 


\section{THEORETICAL EXPLANATION OF APM}

\subsection{Exploring agile in depth}

The definitions of APM are various for different literature above. The term APM spread since 2001 is originated in software development and a document called Agile Manifesto which is signed by professionals and theorists in the technology information area. According to the "Agile Software Development Manifesto", APM has the following four core principles [6]:

(1) Individuals and interactions over processes and tools.

(2) Working software over comprehensive documentation.

(3) Customer collaboration over contract negotiation

(4) Responding to change over following a plan

It questions the traditional PM techniques with the limitation of the inflexibility towards dynamic environment and uncertainties. According to Highsmith [2], six principles are provided for APM to solve the uncertainties and constant business changes:

(1) "Product features deliveries by iteration" means the new version of the product should not only inherit all useful features from the old one, but also delivers new innovative improvements or functions.

(2) "Delivering customer value" is based on collaboration between the design team and the client and whether the design could satisfy or balance the ideal and reality of the customer's demand.

(3) "Search the technical excellence" aims to raise the agility to face the unpredictable change during the project and the opportunity of the project to be more successful.

(4) "Develop adaptive teams" means that self-organizing and self-disciplined teams can be formed by the project manager that can help in succeeding better architectures and requirements.

(5) "Encourage exploration of APM practices" means that the project manager should encourage their team to do more experiments and learning. Learning continuously could help them to follow the updating and developing industry standards or business environment.

(6) "Simplify the development process," allows the staff to work more flexibly, with less bureaucracy and more focus on value-adding activities. Team members are supposed to complete tasks with high quality but meanwhile, they are able to allocate their working time according to own circumstance.

\subsection{Agile methods with scrum}

There are several methods to achieve APM such as Scrum, extreme project management, adaptive project management, while the general model of Scrum is most frequently used. Scrum is an agile process framework that breaks down large and complex projects that it is hard to comprehend at once [7]. When the events cannot be predicted in a complex job situation, the team is able to have an accurate view of the fact in the project and make appropriate adjustments to reach the final goal with the help of the Scrum technique.

The Scrum model is built on three major components: roles, process, and artifacts. Firstly, for roles, there are three major roles in Scrum: Scrum Master, Scrum team and product owner. The Scrum master is the project manager or team leader commonly who is responsible for enacting Scrum values and rules, removing impediments in advance. Then the product owner typically is for achieving product value maximum. He is also responsible for the work of the Scrum team and managing the product backlog who knows the needs to be built in the project and the sequences of these builds progressing. Finally, the Scrum team is a cross-functional team, usually consisting of three-nine members. The leader of this team is likely to change depending on the needs of a specific iteration also called sprint. This team has the authority to decide the essential actions to achieve each sprint.

The Scrum process has six major activities: initial planning, release planning meeting, sprint planning meeting, sprint, daily Scrum meeting, and sprint review. The Figure 1. below shows the macro vision of Scrum process. Initial planning is the fist step as a kind of preparation, the product owner should arrange the product backlog and then get the sprint backlog. Next, the release planning meeting happens at the start of the project which gathers all Scrum roles to set the project guidelines. While the time spent on this meeting is relatively less, since the setting can be modified again in the future meeting. The next process is the sprint planning meeting involved in every member. It can be divided into two stages, for the first part, the product backlog is defined with an ordered list of requirements, meanwhile the sprint goal is determined for each sprint individually. The second part is focusing on creating the sprint backlog or items selection.

After that, the sprint begins which has a limit of one month duration to develop the product. In this period, any external factors should be avoided to interfere with the Scrum team. In addition, the requirements of the project are not allowed to change during this sprint. Usually a daily meeting will take about $15 \mathrm{~min}$ between the Scrum master and the team at a fixed place and time. In this meeting, participants are supposed to answer the 
questions: what you have done since the last Scrum; what you will do until the next Scrum and what obstacles stop you from focusing on your work. The purpose of this meeting is to track the progress of the team, which ensures the project is proceeding in an unimpeded and successful manner.

At the end of a sprint, the sprint review meeting is held to demonstrate the evolution and achieved function to the product owner. From this meeting, the Scrum team is likely to derive lessons in this sprint, which could help them to generate more improvement in the following stages.
The last component of the Scrum model is Scrum artifacts, including product backlog, the sprint backlog, and burn down charts, which can be inspected and adapted with transparency and chances. The product backlog is the requirements and necessity in a product in an ordered list. The sprint backlog is a subset of product backlog items so that a particular sprint is selected with the plan. Lastly, a burn down chart is used to prove information that is easy to understand for each product backlog item during the sprint.

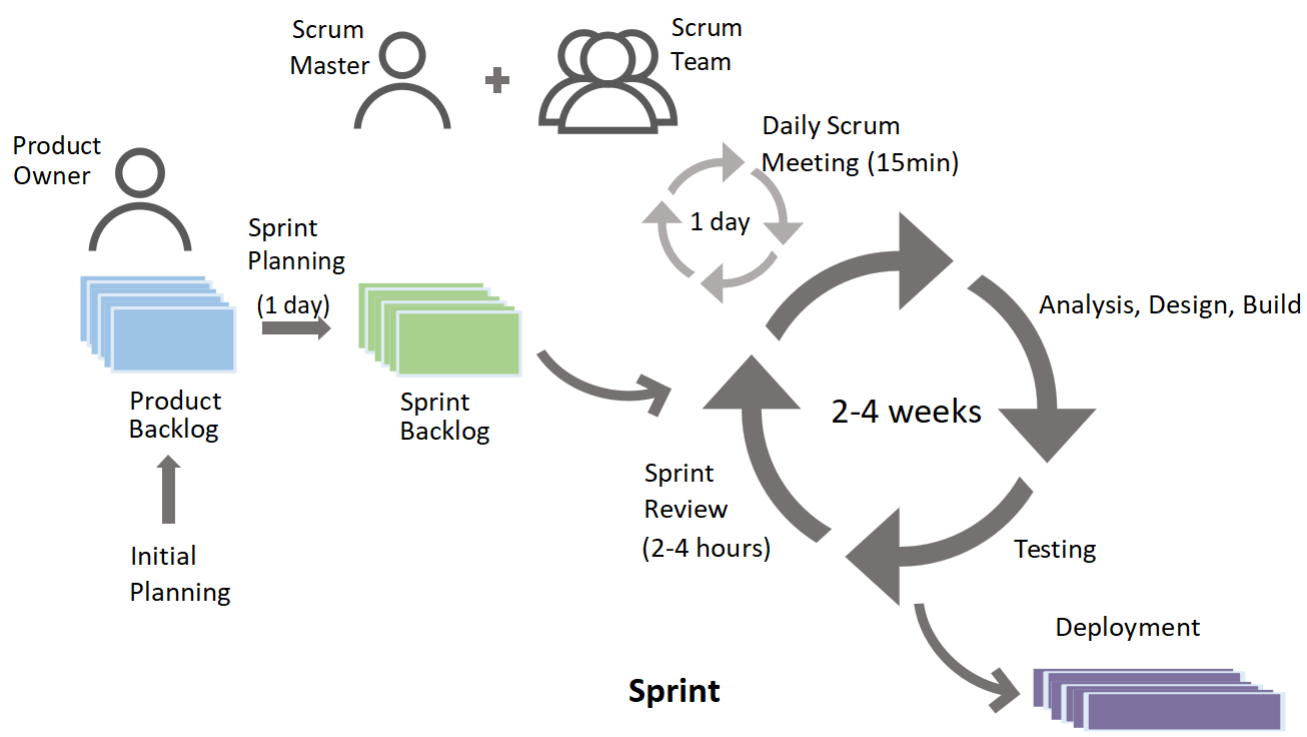

Figure 1. Overview of Scrum process (Adapted from Schwaber [8])

\subsection{Reasons for using APM with Scrum}

The APM is a kind of new managerial concept which is more comparative and suitable than conventional project management, especially in technology based companies. The limitation of conventional PM is not compatible with the complexity and dynamic change of environment [9]. A great amount of time is spent on detailed making planning and constraints rather than concentrated on the product itself. As a result, project performance will not reach the maximum, even the profit for the company as well as the benefits for the team are unsatisfactory. According to Schwaber[10], during the project, about $50 \%$ of the time is spent on communicating requirements, as well as formulating architecture and specifications. However, even if the requirements are communicated, $35 \%$ of the requirements will change in the follow-up process, and $65 \%$ of the required functions are proved to be useless: they are never used or rarely used..

Whereas, the agile method is a more flexible and adaptive variable which means it could more on business achievement and accomplish success criteria, is more efficient and flexible (a single model does not attend all project types) when the complexity and changes shown in the process. APM could increase business value, improve project visibility, growth productivity and so on. For example, redundant meetings, repetitive planning sessions, excess documentation, quality defects and low-value products will be minimized in APM. Therefore, employees are likely to pay more attention to their work rather than relatively irrelevant matters, which means the efficiency and productivity will increase. The software development is incremental by using APM and then it will apply to the product in a short time after accomplishing. Also when some unexpected issues occur, agile projects are better equipped to adapt to changing business requirements. This means the business value is possible to be higher due to quickly deploying and fewer effects from unpredictable changes. The Scrum process is one of the most frequently used methods in APM. The whole Scrum process with sprint often take a regular time cycle. In this period of time, the frequent feedback and communication within the team will help the project more visible and team member more connected. Sprint is regular and each Sprint team presents its work and presents the results that can be always checked and adjusted. 


\section{APM PRACTICAL APPLICATION}

In fact, practical results of a great number of projects have deviations from the expectation. According to a survey [11], the percentage of overdue projects implemented in the information system is 50\% approximately. The Standish Group's 2000 CHAOS survey of 8,000 projects illustrate the similar results: only 26 percentage of the projects were completed on time [12]. It shows five of the top six reasons for failure stem from communication problems between the development team and the customer. Moreover, the cost of many projects exceeds the initial budget. Human, organization, business processes and other factors would result in other failures existing in the project. In order to complete projects successfully, new project approaches are required.

\subsection{Case I in medicine industry}

One case [5] in the Brazilian pharmaceutical industry, Farma Y, presents the useful application of APM from the Scrum perspective. Farma Y established in 2003 mainly produces generic drugs such as antidiabetics, antihypertensive and glucocorticoids. The products of this company are sold on a national scale, which is presented in main drugs and networks. This case focuses on management in medicine about how to control short shelf-life products. About $30 \%$ stock of drugs would have a potential loss, while the APM with Scrum is tried to reduce losses. The project is called the "XYZ project" where the overall period is divided into five sprints, 20 days in each sprint. The goal of these sprints is stated below [5]:

Firstly, providing accurate data for the volume of short shelf-life of the products in stock.

Secondly, filtering consultations of these drugs by class and time horizon (the sprint has to be separated into two parts due to more time consumption).

Thirdly, finding the cost for the associated class. The product owner clarified the requirements (this sprint is split in two as well).

The XYZ Project follows the rules of Scrum strictly Scrum Master, the Product Owner and Scrum Team as the key stakeholder. The Scrum master has good knowledge of Scrum who is responsible for making sure values and rules are planned and the procedure progressing in order. All of this effort is to achieve the sprint goals with the least obstacles and risks. The product owner here aims to improve internal control and business operation effectiveness and less fixed costs. The backlog list for product requirements should be also presented, while this should be discussed with the Scrum master first. Finally, the Scrum team is the people concentrated on IT, who follow the task backlog to reach sprint goals. 4-12 persons work on the same table without any barriers, which simulated the communication and cooperation between them. This project restores the Scrum approach as close as possible. Five Scrum processes proceed orderly based on theories in Scrum. When the first sprint was finished, the following sprints will be released, there is a total of nine requirements that should be meet after all of the sprints accomplishing. The final results should include a document explained the project in specific, technical achievement, future improvement documents and so on.

About 4 months, the XYZ Project came to the end, while the results of the XYZ Project have been used after the first month already. The cost of this project was US\$145,000 and 4-month time consumption, however, US\$291,000 and 7-month long period are estimated by using traditional PM before. APM apparently shows more benefits for the project team, customers and deliverables of this project. The loss of short-life drugs is reduced by the Scrum method. One customer in this case mentioned [5] "within a month, you already have something and can start using it." The Scrum master also claimed [5], "any change in the project scope is quickly addressed, and I consider this as a strength of the agile". When the customer uses the product early, they can discover any problems soon not wait until the end of the project as in traditional PM. For the project team, they could address any mistake in advance, which reduces the effect on later development.

Inevitably, there are still some limitations revealed in this project. One of the issues would be not adaptive to a completely new project management approach due to the great difference from the traditional one. The traditional approach is prescriptive, while Scrum is an iterative and evolutionary approach. The tendency to plan the entire project was constant within the project team. Thus, Scrum master are supposed to make more effort to help employees insist this working pattern, especially for the first sprint. Hindrance in communication between product owner and Scrum team also might be one problem. Product owner usually does not understand the professional knowledge in IT too much such as the program and technical term. Their energy would be distracted to learn technical information. At the same time, Scrum master is also likely to pay some attention to explain this knowledge to the product owner. This external factor would eliminate the efficiency and productivity in the Scrum approach. In this case, the mismatch between theoretical concepts and practical application is still existing. In theory, leaders in Scrum team should be self-manageable and self-organizing teams, in contrast, Scrum master has incorporated this role of leading the Development Team.

\subsection{Case II in government financial projects}

Another application of APM is in government finance projects where the management method shifts 
from traditional PM to a new one. In the case study from Chris Kraft [13], a federal shared services provider (FSSP) evaluate APM and recommend projects to use APM with Scrum. This update is due to the high risks and large scale of some projects related to accounting and finance in large enterprise resource planning (ERP) or other commercial off-the-shelf (COTS) products. The conventional method usually has a low chance for stakeholder and customer engagement. When facing customer feedback or environment fluctuation, the reaction is too sluggish to develop with these changes. After AMP is applied to the production, FSSP starts to deploy the functionality in the sprint immediately. The procedure has been introduced in the above beginning at the releasing meeting, and then Scrum planning meeting, sprint, Scrum daily meeting and review meeting will take place in the sequence. Thus, the shifting from traditional to agile is already successful with more engagement from customers. At the same time, the Scrum team is also able to determine the best leverage agile to achieve the greatest value. The Government Accountability Office (GAO) presents some effectiveness by using APM, for instance, high visibility and adaption, low risk in financial management in ERP and COTS [10].

Nevertheless, there are still a few challenges existing like struggles with procurement practices, unclear guidance on APM and difficulty to have close team collaboration. Procurement practices are strategies in authorities to make company purchasing decisions. Using the APM approach means the government is likely to buy technology or software that are not physical, so few people can imagine what it exactly looks like. The technology industry is floating without boundaries, and production should be updated in a short time. Thus, the stuff acquired by the government probably has a huge difference from initial expectations. In addition, agile is a new type of project management method, masters or leaders are still in the experimental stage who lack of experience. Therefore, the regulation about how to implement this method is unclear, and teams would be confused about this new pattern. However, close team collaboration should also take a long period to achieve. In traditional PM, the members are not familiar with each other, only a few communication per day with colleagues, while in APM, frequent meetings will take place within the team and members should know each other to have better cooperation. This may make some people not adaptable in this new circumstance. Thus, applying a new management approach should consider the overall situation and be incremental.

\section{CONCLUSION}

In conclusion, this paper has a clear explanation of concepts of APM and the Scrum method. APM can adjust the plan with changes in the environment and concentrate on business results and achievement of multiple success criteria. The Scrum is an agile process framework throughout the product development cycle. Visibility, flexibility and are the main characteristics of using APM with Scrum. These features brings higher productivity and efficiency with less risks as well as more close collaboration between customers and project teams. Then two applications of this approach have been presented, the APM with scrum in stock management module in a Brazilian pharmaceutical company and authority financial management. In medicine company, it can be found that the cost of using APM is much less than traditional PM and the product could be already used in month period. after that, the project team is able to improve and address mistakes in their results. Also the stock of drug has great improvement with less losses. For government project, the shift from conventional to APM rise the safety and customer engagement. Although these two cases show several benefits of using APM, it cannot present APM could be also successfully used in other industries. Still some challenges by applying APM with Scrum are presented in the article above. For example, unclear guidance on APM, hindrance in communication between product owner and Scrum team and difficulty to have close team collaboration, these issues may result in less effective in this new approach, and the advantages will not be such evident as the theories predicted.

For future research, the exploration will be in person rather than based on cases from the literature if APM could be used in more industries like electronic devices, food and even in service. Also more numerical results could be provided to make the paper more persuasive by construction a management model that could see the performance of APM apparently. In addition, the publication time of existing literature on this topic is relatively far from today, therefore, the next goal might be to find whether APM is suitable and popular to use in nowadays conditions or not.

\section{REFERENCES}

[1] Conforto, E.C., and Amaral, D.C. Agile Project Management and Stage-Gate Model-A Hybrid Framework for Technology-Based Companies. Journal of Engineering and Technology Management, 2016(40): 1-14.

[2] Highsmith, J.A. Agile Project Management Creating Innovative Products. Jim Highsmith. 1st ed., Addison-Wesley, 2004.

[3] Augustine, S., Payne, B., Sencindiver, F. and Woodcock, S. Agile project management: steering from the edges. Communications of the ACM, V2005, 48(12): 85-89. 
[4] DeCarlo, D. Extreme Project Management: Using Leadership, Principles, and Tools to Deliver Value in the Face of Volatility. Jossey-Bass, San Francisco, CA, 2004.

[5] Adrialdo, A., Argoud, A.R.T.T., De Camargo Junior, J.B., and Pedro Domingos Antoniolli. Agile Project Management with Scrum: A Case Study of a Brazilian Pharmaceutical Company IT Project. International Journal of Managing Projects in Business, 2017, 10(1): 121-42. Web.

[6] Hohl, P., Klünder, J., Van Bennekum, A., Lockard, R., Gifford, J., Münch, J., Stupperich, M., and Schneider, K. Back to the Future: Origins and Directions of the "Agile Manifesto"-views of the Originators. Journal of Software Engineering Research and Development, 2018, 6(1): 1-27. Web.

[7] Cervone, H.F. Understanding Agile Project Management Methods Using Scrum. OCLC Systems \& Services, 2011, 27(1): 18-22.

[8] Schwaber, K. Agile Project Management with Scrum, Microsoft Press, Redmond, WA, 2004.

[9] Ciric, D., Lalic, B., Gracanin, D., Tasic, N., Delic, M., and Medic, N. Agile vs. Traditional Approach in Project Management: Strategies, Challenges and Reasons to Introduce Agile. Procedia Manufacturing, 2019(39): 1407-414.

[10] Schwaber, K. The Enterprise and Scrum. Microsoft Press, Redmond, WA, 2007.

[11] Antlova, K. Agile Approach in the Project Management of the Czech Companies. Procedia Technology, 2014(16): 929-933.

[12] Briones-Peñalver, A.J., Bernal-Conesa,J.A., and De Nieves Nieto, C. Knowledge and Innovation Management Model. Its Influence on Technology Transfer and Performance in Spanish Defence Industry. International Entrepreneurship and Management Journal, 2020, 16(2): 595-615.

[13] Kraft, C. Agile Project Management on Government Finance Projects. The Journal of Government Financial Management, 2018, 67(1): 12-18. 